This book is interesting and it is very well produced. It may be recommended to all those who are interested in internal medicine.

$$
\text { K.N.V.P. }
$$

\section{GENETICS IN OPHTHALMOLOGY}

By Prof. Arnold Sorsby. Pp. xi +265 , with 233 illustrations. London: Butterworth \& Co. I95I. 42s.

This book is divided into three sections. The first, of 68 pages, gives an account of the theoretical background of modern genetics, with a consideration of the interplay of hereditary and environmental factors. The second section, of 127 pages, contains a discussion of the clinical aspects of isolated ocular anomalies, with a critical analysis of the genetic factors involved. The third section, of $4 \mathrm{r}$ pages, deals with the clinical picture and genetics of generalized disorders with ocular manifestations.

The quality of the clinical descriptions is excellent, as is to be expected from the author, who is Research Professor in Ophthalmology at the Royal College of Surgeons and the Royal Eye Hospital. Inherited abnormalities of the eye lend themselves to pictorial representation, and the illustrations, many in colour, are an outstanding feature of this volume.

This production is an excellent contribution to modern genetical literature. It is therefore all the more unfortunate that no source is given for many of the statements made in the texts; it is hoped that this may be remedied in the next edition of the book, enabling it to serve in addition as a reliable guide to the original literature on the subject.

\section{MODERN TRENDS IN NEUROLOGY}

Edited by Anthony Feiling, B.A., M.D., F.R.C.P. Pp. ix +717 , with 202 illustrations. London: Butterworth \& Co. 195I. 63s.

The contents of this volume are: (I) Conduction of the Nervous Impulse (W. A. H. Rushton); (2) The Frontal Lobes and their Functions (D. Denny-Brown); (3) Headache (E. Charles Kunkle and H. G. Wolff); (4) The Cerebral Palsies of Infancy (William G. Wyllie); (5) Arachnoiditis (J. St. C. Elkington); (6) Meningitis (J. B. Gaylor); (7) Acute Poliomyelitis (Douglas McAlpine); (8) Radiculitis (Redvers Ironside); (9) Syphilis of the Nervous System (C. Worster-Drought); (10) Abscess of the Brain (Joe Pennybacker); (I I) Intracranial Tumours (D. W. C. Northfield and Dorothy Russell); (12) Chronic Subdural Effusions (Valentine Logue); (13) Intracranial Aneurysms (S. W. Meadows); (14) Certain Vascular Diseases of the Nervous System; Part I, Temporal arteritis; Part II, Cerebral thrombo-angiitis obliterans; Part III, Thrombosis of the carotid artery (P. C. P. Cloake); Part IV, Polyarteritis nodosa of the nervous system (Gilbert S. Hall); ( 15 ) Myasthenia
Gravis (S. Nevin); (16) Rupture of the Intervertebral Disc (William Jason Mixter); (17) Nervous and Vascular Pressure Syndromes of the Thoracic Inlet and Cervico-Axillary Canal (F. M. R. Walshe); (18) Epilepsy (Michael Kremer); (19) Clinical Electroencephalography (Denis Williams); (20) Diagnostic Neuroradiology (J. W. D. Bull).

The contributions are without exception of a very high standard. The subject matter is in most instances not confined merely to recent advances, but consists of a balanced review of the development and of the present state of our knowledge. In brief the words of the Editor may be echoed: 'It is believed that neurologists will find this book a valuable and even an indispensable addition to their library.'

\section{DISEASE IN INFANCY AND CHILDHOOD}

By R. W..B. Ellis, O.B.E., M.A., M.D., 'F.R.C.P. Pp. vii +695 , with 300 illustrations. Edinburgh: E. \& S. Livingstone. 1951. $42 \mathrm{~s}$.

The preface states that this book is primarily intended to emphasize the features of young individuals which determine the response to disease processes and to distinguish the difference between this response and that of adults. Emphasis, therefore, is on the diseases of infancy and children rather than on normal development and feeding.

The book is extraordinarily comprehensive and includes descriptions of a great variety of rare con ditions as well as the more common disorders. It is very up to date and refers to many recent advances in paediatrics. The sections on the newborn infant and congenital malformations are especially complete and reflect the recent progress in the understanding of these conditions and their aetiology.

The student may find that his interest in the more common disorders is distracted by the rarities while the general practitioner will find reference to all the conditions which he may chance to meet but might wish for a greater detail in advice as to treatment. Taken in conjunction with the author's 'Child Health and Development' the survey of paediatrics is extensive. The quality of production is very high, especially in $\mathrm{X}$-rays and photographs.

\section{DIAGNOSIS AND TREATMENT OF TUMOURS OF THE HEAD AND NECK}

By G. E. WARD, M.D., D.Sc., F.A.C.S., and J. W. HeNDRICK, M.D., M.S. Pp. xv + 832, with 637 figures. Baltimore: The Williams \& Wilkins Co. London: Baillière, Tindall \& Cox. $195^{\circ}$. Ii4s.

This work deals comprehensively with the pathology, clinical manifestations, and treatment of tumours of the head and neck, both benign and malignant; it includes the territories of the otorhino-laryngologist, and outlines the methods of 
plastic repair, but excludes the sphere of the neurosurgeon. Although a massive bibliography follows each chapter, and although a considerable pumber of introductory pages are devoted to embryology, the book is essentially the expression of the authors' personal views on the surgery and radiotherapy of the head and neck. The opinions which are advanced are doubly valuable in that they are the fruit of many years of direct experience and are expressed with the greatest clarity. The book is rendered the more readable by the avoidance of all but the most significant statistics and by the inclusion of a profusion of illustrations.

R.S.M.

\section{ENGLISH-GERMAN MEDICAL DICTIONARY}

By F. S. Schoenewald, M.D.Berlin. Pp. viii + 242. London: H. K. Lewis. 1951. 35 s.

A handy well-printed volume; perhaps not quite so useful as its German-English counterpart. The two are strongly recommended and easily used volumes.

\section{A HISTORY OF MEDICINE}

\section{Vol. I: Primitive and Archaic Medicine}

By Henry E. Sigerist, M.D., D.LitT., LL.D.,

DR.H.C. Pp. xxi +564 , with 104 illustrations.

New York: Oxford University Press. (London:

Geoffrey Cumberlege.) 195I. 45s.

Professor Sigerist has often placed the world of learning in his debt. He now enriches it with a volume, the first of a series of eight on the history of medicine, which is the outcome of 25 years of research and teaching. The gratitude of the medical profession and of all scholars is due not only to the author, but to Yale University and those individuals, trusts and foundations whose wisdom and generosity has made this great project possible.

- Professor Sigerist has approached his subject from an ecological standpoint, including in his field all that is understood by the term social medicine. His work provides a new basis for that concept; it may be hoped that it will also broaden the outlook of those medical historians whose method is genealogical and for whom the echoing corridors of time are straight avenues of progress, reassuringly patrolled by 'fathers' each with his discovery beside him. Professor Sigerist's field is global, his period limited only by the material available. He vindicates the claim made by Professor John Fulton in the preface: 'Dr. Sigerist is probably the only living scholar who has both the training and the vision to approach the development of medicine on this vast scale.' The volume covers primitive medicine and archaic medicine-Egyptian and Mesopotamian. From a study of material in museums and, more especially, of palaeopathological specimens, a comprehensive picture is given of periods and races for which no written records, or only limited ones, exist. In a style simple and intimate the author guides his readers effortlessly through the labyrinthine paths of folklore, magic and religion, explaining philosophical, theological and empirico-rational systems of medicine, drawing attention to the literature, art and music of long dead civilisations, and the social and economic structure of their societies. An attitude of scientific objectivity is maintained throughout. Such selfdiscipline might easily produce a colourless statement of fact, but the human interest is preserved by means of numerous quotations from contemporary sources. As befits a great teacher, Professor Sigerist is didactic; when cautious or speculative comments are made, they are a reminder of the extreme antiquity of the sources on which he has drawn, a fact which the reader easily forgets when confronted with descriptions so vivid. The book is fully illustrated, the collections of the Wellcome Historical Medical Museum being the source of many of the photographs. It is admirably.printed. The author gives copious references, notes, and selective bibliographies. This volume can be regarded as a valuable work of reference, but it is a great deal more than that: 'The picture we carry of our past is a powerful instrument of life ' (p. 30) and Professor Sigerist has through his researches given a new dignity to the profession of medicine.

THE PHARMACOLOGY AND THERAPEUTICS OF THE MATERIA MEDICA

By Walter J. Dilling, M.B., Ch.B., M.P.S (HoN.). rgth Edition. Pp. xxxii +598 ? London: Cassell \& Co. I95I. 2 rs.

This comprehensive book on the pharmaceutical, pharmacological and therapeutic aspects of drugs has reached its rgth edition, but unfortunately its appearance has been delayed until after the death of its well-known author, Professor Walter J. Dilling. Much new material has been incorporated into this latest edition. This has meant, firstly, extensive revision to conform with the official preparations of the British Pharmacopoeia, 1948, and secondly, the addition of new sections on important new groups of drugs such as antibiotics and other chemotherapeutic remedies, Vitamin Bi2, folic acid and intravenous iron in anaemias, cortisone and adrenocortico-tropic hormone in rheumatoid arthritis and musccular relaxants in anaesthesia. The attitude to pharmacology is perhaps old-fashioned, but the book is packed with information of value to students and practitioners of medicine.

C.A.K.

\section{MODERN TRENDS IN PAEDIATRICS}

Edited by the late Sir Leonard Parsons, M.D., F.R.S., F.R.C.P. Pp. $x+601$, with r ro illustrations. London: Butterworth \& Co. 195 r. $55 \mathrm{~s}$.

This is a book which cannot fail to be of interest to all postgraduates whose work touches on paediat- 